Document downloaded from:

http://hdl.handle.net/10251/156094

This paper must be cited as:

Tanleque-Alberto, F.; Juan-Borras, MDS.; Escriche Roberto, MI. (2019). Quality parameters, pollen and volatile profiles of honey from North and Central Mozambique. Food Chemistry. 277:543-553. https://doi.org/10.1016/j.foodchem.2018.11.007

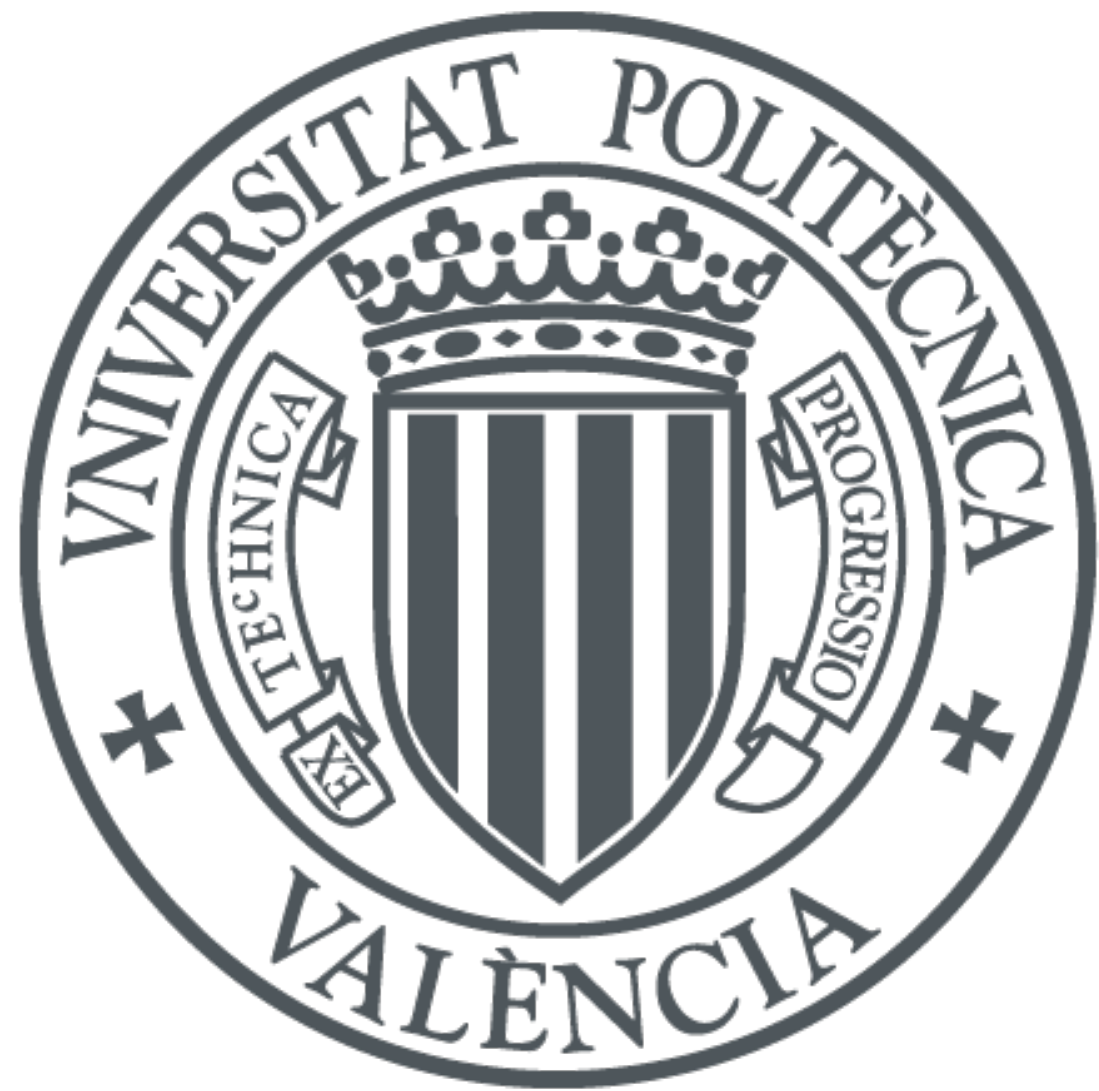

The final publication is available at

https://doi.org/10.1016/j.foodchem.2018.11.007

Copyright Elsevier

Additional Information 


\section{Quality parameters, pollen and volatile profiles of honey from North and}

2 Central Mozambique

3 Fernando Tanleque-Alberto ${ }^{\mathrm{a}}$, Marisol Juan-Borrás ${ }^{\mathrm{b}}$, Isabel Escriche ${ }^{\mathrm{b}^{*}}$

4 aDepartamento de Ciencias Naturais e Matemática. Universidade Pedagógica-Nampula,

5 Mozambique

6 b Institute of Food Engineering for Development (IUIAD). Food Technology Department (DTA).

7 Universitat Politècnica de València. Valencia, Spain

$8 \quad *$ Corresponding author: Isabel Escriche, iescrich@tal.upv.es;

$9 \quad$ Tel.: +34-963877366; fax: +34-963877369

10 Abstract

11 Honey from different provinces of North and Central Mozambique was characterised considering their 12 physicochemical quality parameters, colour, sugars, total antioxidants, pollen analysis and volatile profile. Flora that surrounds the hives, and the apicultural practices also influence in their characteristics. According to a similar pollen spectrum, eight types of honey were found. In these, the predominant pollens were: I-Astragalus type; II-Acanthus sp; III-Celastraceae; IV-Brassicaceae; VAnacardiaceae and Astragalus type; VI-Astragalus type and Myrtaceae; VII-Asteraceae family and VIII-unknown. Group I (from Nampula), especially distanced itself from the others mainly due to the special abundance of certain compounds (alcohols, aldehydes, esters, acids and terpenes). The presence of furan compounds largely identified in Sofala and Manica honeys could be due to inadequate beekeeping practices or storage conditions. A discriminant analysis correctly classified $96.7 \%$ of the groups, being electrical conductivity and moisture followed by the volatile-compound $3-$

22 Methylbutan-1-ol and the free acidity, the variables that most contributed.

Keywords: Mozambique, honey, pollen, physicochemical quality parameters, volatile-compounds.

\section{Introduction}

Mozambique, located in the Southeast coast of Africa is one of the poorest countries in the world.

Here, apiculture does not play an important social, economic or environmental role but it has potential 
to increase the sustainability of poor rural communities (Bradbear, 2005; Serem \& Bester, 2012). North and Central regions of Mozambique enjoy a favourable climate and have sufficient natural resources, particularly vast forest areas rich in melliferous flora ideal for beekeeping. At present, honey production in Mozambique is very low, about 600 tons/year (FAOSTAT, 2016), with a growing trend in the last 5 years. However, due to the availability of agro-ecological resources, the production capacity could reach 3,600 tons/ year (Jooste \& Smith, 2004).

In Mozambique, there are several possible benefits to beekeeping. It could be an attractive income generating activity for smallholder farmers and be exploited by women of rural populations. There is no doubt that beekeeping can help generate social change and play an important role in society while creating sustainable livelihoods. In addition, it can favour the development of many different sectors within society: vendors, carpenters who manufacture beehives, garment makers, protective clothes, and packaging processors. All this keeping in mind the contribution of apiculture for the development of agriculture and the environment associated with the increase of pollination.

In the last years, the world market demands differentiated agro-alimentary products with specific characteristics based on the following criteria: botanical or geographical origin, quality and safety, specific organoleptic or nutritional characteristics, among others (Borrás, Domenech, Hellebrandova, \& Escriche, 2014). For this reason, there is a large number of global research studies about the characteristics of honey; however, there are very few focused on properties of African honeys. Among these, it is worth mentioning those papers of different African countries: Ethiopia (Sime, Atlabachew, Redi-Abshiroand, \& Zewde, 2015); Burkina Faso (Meda, Lamien, Romito, Millogo, \& Nacoulma, 2005; Nombré, Schweitzer, Boussim, \& Rasolodimby, 2010; Paul, Issa, Kwamé, \& Joseph, 2013; Escriche, Oroian, Visquert, Gras, \& Vidal, 2016); South Africa (Serem \& Bester, 2012); Sudan (Makawi, Gadkariem, \& Ayoub, 2009); Tunisia (Martos, Cossentini, Ferreres, \& Tomas-Barbera, 1997); Morroco (Malika, Mohamed, \& Chakib, 2005) and Mozambique (Escriche, Tanleque-Alberto, Visquert, \& Oroian, 2017). Generally, those papers are focused on physicochemical and rheological 
52 properties. However, they do not deal with other important characteristics appreciated by the consumers such as; aroma and colour, or even the origin (botanical or geographical) that also provide added value in the marketplace. With respect to origin, pollen present in honey is "the witness" of the flowers that the bee has visited, since its entrainment by adhesion occurred when they collect the nectar. Therefore, the pollen analysis (consisting in the recognition of the pollen grains morphology of the different botanical species) is a powerful tool that allows knowing the botanical and geographical origin of honey (Oddo et al., 2004; Juan-Borrás et al., 2014).

59 Considering Mozambiquean honey, there is an almost total lack of scientific data; therefore, it would be interesting to expand its knowledge, especially related to quality indicators. Advertising could attract the attention of local authorities in charge of the national regulation of this product. This will

62 facilitate its quality control, thus promoting the commercialization in local and international markets and to support and further develop the apiculture. All this in the context of the mandatory fulfilment of the international requirements with regards to specific quality criteria parameters (Council Directive 2001/110 relating to honey, 2002) and intrinsic characteristic that also provide added value in the marketplace.

Taking this into consideration, the aim of this work was to characterise honey from different provinces of North and Central Mozambique in terms of their physicochemical quality parameters, colour, sugars, pollen analysis and volatile profile. This will serve as useful information for the future regulation of honey from this region.

\section{$71 \quad 2 . \quad$ Materials and Methods}

\section{$72 \quad$ 2.1. Collection samples}

Seventy honey samples from northern and central Mozambique were analysed in the present study:

7420 from Nampula (districts of Moma, Angoche and Ribáuè) in the north and 15 from Zambezia, 15 
and 2015. Honey from Nampula and Zambezia was obtained using traditional beehives (made with local resources such as twigs, trunks and barks) and harvesting methods. However, samples from Sofala (packaged by Mozambique honey Company) and the majority of Manica samples were obtained and processed using more modern procedures.

\subsection{Physicochemical quality parameters: colour and sugar analyses}

The methods of the International Honey Commission (Bogdanov, 2009) were applied to determine the physicochemical quality parameters: Moisture by refractrometry (Abbe-type T1 Atago, Washington, USA, and the Chataway table); hydroxymethylfurfural (HMF) by HPLC-UV with a Compact LC 1120 (Agilent Technologies California, USA) using a column ZORBAX Eclipse Plus C18 (4.6 x $150 \mathrm{~mm}, 5 \mu \mathrm{m}$ particle size, Agilent Technologies, USA) USA), with isocratic mode, water: acetonitrile (25:75); electrical conductivity by a conductimeter C830 (Crison Instrument, Barcelona, Spain,); pH, free and lactonic acidity by potentiometric titration with a 905 Titrando (Metrohm, Herisau, Switzerland). Furthermore, colour was measured using a millimetre Pfund scale Honey Colour Analyser C221 (Hanna Instruments, Barcelona, Spain) (Escriche et al., 2016). Water activity $\left(\mathrm{a}_{\mathrm{w}}\right)$ was determined at $25^{\circ} \mathrm{C}\left( \pm 0.2^{\circ} \mathrm{C}\right)$ with an electronic dew point water activity meter, Aqualab Series 4 TE (Decagon Devices, Washington, USA), fitted with a temperature-controlled system (Escriche et al., 2016). The content of sugar samples (glucose, fructose, and sucrose) was determined with a HPLC Compact LC 1120 (Agilent Technologies, California, USA), coupled to an Evaporative Light Scattering detector 1200 (Agilent Technologies, Ratingen, Germany), equipped with a chromatographic Carbohydrate column $(4.6 \times 250 \mathrm{~mm}, 4 \mu \mathrm{m}$ particle size, Waters, Ireland). The total antioxidant activity was measured based on the scavenging activities of the stable 2,2-diphenyl-1picrylhydrazyl (DPPH) (Sigma-Aldrich, Madrid, Spain), in a UV-Vis spectrophotometer Helios alpha (Thermo Scientific, England) (Juan-Borrás, Soto, Gil-Sánchez, Pascual-Maté, \& Escriche, 2017). All determinations were carried out in triplicate. 
The laboratory where this study was carried out (Laboratory of Quality Control of Honey and apiculture products of Universitat Politecnica de Valencia) participated with the described methods in the last edition (June-August 2018) of "FAPAS ${ }^{\circledR}$ Proficiency Test specifically designed for Quality 103 indicators of Honey" (accredited by UKAS as complying with the requirement of ISO/IEC 104 17043:2010). The z-score values resulted from this last edition for all the parameters analyzed in the present study ranged from -0.2 to 1.8 . Considering that acceptable range must be $-2 \leq \mathrm{z} \leq 2$, the validity of the analytical methods is proven. Other authors also reported the Proficiency Test procedure as the best way to achieve this goal (Camino-Sánchez, et al., 2012; Anagnostopoulos \& Miliadis, 2013; De Girolamo, et al., 2017).

The total antioxidant activity in honey is the only parameter, which was not a target of the FAPAS

Proficiency Test. For this reason, this parameter had to be validated by an internal and separate procedure [linearity $=0.9982$; repeatability estimated as $\mathrm{RSD}=5.3 \%$ and reproducibility $=8.0(\mathrm{n}=5)$ and accuracy calculated as recovery $=84 \%-110 \%]$.

\subsection{Pollen analysis}

114 The melissopalynologycal analyses were carried out as reported by Juan-Borrás et al., (2014). In 115 brief, $10 \mathrm{~g}$ of honey was dissolved in $20 \mathrm{~mL}$ of acidulated water (sulphuric acid, 5\%) and then centrifuged. After the supernatant was discarded, and the sediment was re-dissolved with distilled water and centrifuged again. The residue obtained was then observed under $\times 40$ magnification using

a Light optical microscope (Zeiss Axiolab, Göttingen, Germany). Pollen grains were identified considering general palynological databases (Gosling, Miller, \& Livingstone, 2013; Schüler \& Hemp, 2016; Palynological Database on line, 2018; Hyde, Wursten, Ballings, \& Coates Palgrave, 2018); and the existing information about the flora present in the areas of honey collection (Crane, 1973; Johannsmeier, 2016).

In the same manner to what was performed for ensuring the quality physicochemical parameters, colour and sugar analyses results, this laboratory has participated in one of the few Proficiency Tests 
125 specifically designed for pollen analysis in honey, organized by the "Laboratorio Arbitral Agroalimentario-Ministerio de Agricultura Pesca y Alimentación (LAA-MAPAMA) (Spain)" in cooperation with "Gabinete de Servicios para la Calidad (SGCLA)". In this case our Z-score was $128-0.07$ (within the before mentioned acceptable range), which indicates that the validity of the pollen analysis is demonstrated.

\subsection{Volatile compound analysis}

131 The extraction of volatile compounds was done by the purge and trap methodology $\left(45^{\circ} \mathrm{C}\right.$ for 20 min) using purified nitrogen (100 $\mathrm{mL} \mathrm{min}^{-1}$ ) (Juan-Borrás et al., 2014). The compounds were trapped in a glass tube packed with Tenax TA (20-35 mesh), thermally desorbed $\left(220^{\circ} \mathrm{C}\right.$ for $10 \mathrm{~min}$ at $10 \mathrm{~mL}$ $\min ^{-1}$ helium flow), cryofocused in a cold trap at $-30^{\circ} \mathrm{C}$, and then transferred into a capillary column by heating the cold trap to $250^{\circ} \mathrm{C}$ (rate of $99^{\circ} \mathrm{C} / \mathrm{s}$ ) using a TurboMatrix TD (Perkin Elmer TM, CTUSA). Thereafter, the extracted volatile compounds were separated and identified in a GC-MS (Finnigan TRACETM MS, Thermo Quest, Austin, USA) equipped with a DB-WAX capillary column (SGE, Australia) (60 m length, $0.32 \mathrm{~mm}$ i.d.,1.0 $\mu \mathrm{m}$ film thickness), using helium as a carrier gas (flow rate of $\left.1 \mathrm{~mL} \mathrm{~min}{ }^{-1}\right)$. The temperature oven programme was: from $40^{\circ} \mathrm{C}$ (2-minute hold time) to $190^{\circ} \mathrm{C}$ at $4^{\circ} \mathrm{C} \min ^{-1}$ (11-minute hold time) and finally to $220^{\circ} \mathrm{C}$ at $8^{\circ} \mathrm{C} \min ^{-1}$ (8-minute hold time). Electron ionization mass spectra were recorded in impact ionization mode at $70 \mathrm{eV}$ (mass range of $\mathrm{m} / \mathrm{z} 33-433$ ). 2-Pentanol was used as an internal standard. Three extracts were obtained for each sample.

The identification of isolated volatile compounds was performed by comparing their mass spectra, retention times and linear retention indices against those obtained from authentic standards. When authentic standards were not available, the compounds were tentatively identified by comparing their mass spectra (m/z values of the most important ions) with those from the NIST library (National Institute of Standards and Technology) as well as the linear retention indices of all the compounds. These indices were obtained by injecting a range of $\mathrm{C}_{8}$ to $\mathrm{C}_{20}$ alkanes into the Tenax applying the same temperature-programme as the samples. The variables used in the statistical analysis for differentiation 
between honeys were the semi-quantified compounds data since authentic commercial standards for all identified compounds were not always possible. This data was obtained considering the relative area between the peak areas of each compound and the peak area of the internal standard, assuming a response factor equal to one and expressed as $\mu \mathrm{g}$ of compound/100 $\mathrm{g}$ of honey (Juan-Borrás et al., 154 2014). study the influence of the province were the harvesting took place on the physicochemical quality

\subsection{Statistical analysis}

An analysis of variance (ANOVA) (using Statgraphics Centurion for Windows) was carried out to parameters, colour, sugars and volatile compounds. The method used for multiple comparisons was the LSD test (least significant difference) with a significance level $\alpha=0.05$. Furthermore, a Principal Component Analysis (PCA) data was applied by means of the software Unscrambler X.10. Stepwise linear discriminant analyses were carried out using the 'forward' procedure, which begins with no variables in the model and adds the variables with the greatest discriminating power (SPSS 16.0).

\section{Results and discussion}

\subsection{Physicochemical quality parameters, colour and sugar content}

With the aim of facilitating the comparison of variability patterns between "province" where the harvesting took place, Figure1 shows the box and whisker plots for all the physicochemical quality parameters (moisture, aw, HMF, electrical conductivity, total antioxidant, free acidity, lactonic acidity and $\mathrm{pH})$ as well as fructose, glucose, fructose/glucose ratio $(\mathrm{F} / \mathrm{G})$ and colour Pfund. According to the ANOVA analysis performed (data not shown), most parameters among provinces showed statistically significant differences, with electrical conductivity, colour, and F/G ratio being the only exception. However, the main cause of these exceptions is primarily due to the large range of variability observed for these parameters. For example, these values in Nampula samples ranged from 0.30 to $1.54 \mathrm{mS} / \mathrm{cm}$; 
17354 to $152 \mathrm{~mm}$ Pfund scale; and 0.90 to 1.52 (F/G ratio), respectively. Considering the F-ratio values 174 from ANOVA, moisture and $\mathrm{a}_{\mathrm{w}}$ are the parameters most affected by the factor province.

175 In general, Manica and Sofala samples had the lowest moisture contents, fulfilling the international 176 criteria for moisture (less than $20 \mathrm{~g} / 100 \mathrm{~g}$ ) (Council Directive 2001/110 relating to honey, 2002). This 177 condition has a positive influence on the quality of the honey harvested in both provinces because low 178 moisture levels slow down the probability of fermentation. The high stability of the honey from both 179 provinces, especially from Manica, also remains patent due to the low levels of $\mathrm{a}_{\mathrm{w}}$. However, in 180 Nampula, some samples exceeded the recommended limit of moisture and because of their high $\mathrm{a}_{\mathrm{w}}$, 181 are at risk of presenting different problems of quality alteration. All these alterations, although not 182 harmful for human health, may be the cause of negative appearance and consequently having an adverse effect on its market value. The highest moisture levels found in honey samples from specific areas of Mozambique as is the case of Nampula, could be associated with pluviosity conditions such In fact, Nampula located in the north, is humid with an average annual rainfall around 2,000 mm, in Manica and Sofala, in the centre, only 1,000 mm (Zandamela, 2008). Different authors reported that 187 the fermentation processes of honey could be accelerated in humid areas and rainy seasons, resulting 188 in a more vulnerable honey (Tornuk et al., 2013; Silva, Gauche, Gonzaga, Costa, \& Fett, 2016). In addition to the climate conditions, inadequate beekeeping practices is another important factor that can affect the final moisture content; for instance, if it is extracted before the bees are able to dry it with their wings or if the honey is stored (after harvesting) in a very humid environment (due to the honey's 192 higroscopicity). Keeping in line with good beekeeping practices, another important parameter to 193 consider is HMF, since it can increase during handling, extraction, conditioning, or storage operations and mostly as a result of thermal treatments (time and temperature) (Silva et al., 2016). In the present work HMF is ranged by province among the following minimum and maximum values: 1.1-65.0 $\mathrm{mg} / \mathrm{kg}$ in Nampula; $25.3-60.6 \mathrm{mg} / \mathrm{kg}$ in Zambezia; $11.2-114.5 \mathrm{mg} / \mathrm{kg}$ in Manica and 2.2-47.19 mg/kg in Sofala. Although, in many cases these honeys exceeded the generally admitted maximum of 40 
$\mathrm{mg} / \mathrm{kg}$, it must be considered that Mozambique has a tropical climate and therefore this parameter up to $80 \mathrm{mg} / \mathrm{kg}$ is permitted (Council Directive 2001/110 relating to honey, 2002). When this value is exceeded, honey is deemed unacceptable to be commercialised. The great dispersion observed for HMF within the same province, highlights the importance of the beekeepers role. If some beekeepers obtain honey with very low HMF values, others in the same region should do the same. All this suggests that training in good practices is the first step in guaranteeing good quality honey that has the potential of being sold on international markets.

In contrast to the above mentioned parameters, the dispersion of colour in most cases (54-152 mm Pfund in Nampula; 140-150 mm Pfund in Zambezia; 88-150 mm Pfund in Manica and 84-137 mm Pfund in Sofala) and electrical conductivity values $(0.30-1.54 \mathrm{mS} / \mathrm{cm}$ in Nampula; $1.21-1.39 \mathrm{mS} / \mathrm{cm}$ in Zambezia; $0.46-1.33 \mathrm{mS} / \mathrm{cm}$ in Manica and $0.39-1.36 \mathrm{mS} / \mathrm{cm}$ in Sofala) could be logical as a consequence of the flora present in the different geographic areas. This is because both parameters directly depend on the nectar or secretions of plants visited by bees. Since all Zambezia samples had electrical conductivity values above $0.80 \mathrm{mS} / \mathrm{cm}$, they could be considered as honeydew honeys. However, in the other provinces, the electrical conductivity was indistinctly above and below this value, for this reason, these honeys could come from both nectar of flowers or secretions of plants (Council Directive 2001/110 relating to honey, 2002). The wide dispersion in the values of electrical conductivity observed in the present work is in line with those reported for honey samples from Manica and Sofala (Zandamela, 2008), although these authors found values of up to $2.62 \mathrm{mS} / \mathrm{cm}$. Colour and electrical conductivity parameters are related to each other, because the darker the colour, the higher the mineral content resulting in higher conductivity (Juan-Borrás et al., 2014). Moreover, this trend could be generally correlated to the antioxidant activity levels to the point that, in general, the greater the intensity of colour and conductivity, the higher the phenolic total content of a honey (Juan-Borrás et al., 2017). In fact, in the present work, one sample from Nampula simultaneously had the highest 
222 total antioxidant activity (40.0 $\mathrm{mg}$ Trolox equivalent/100 g), colour (152 mm Pfund) and electrical conductivity $(1.54 \mathrm{mS} / \mathrm{cm})$.

224 As usual in honey, fructose in all samples was the most abundant sugar, followed by glucose. The average values for fructose was 39.1, 41.3, 45.1 and $39.2 \mathrm{~g} / 100 \mathrm{~g}$, and for glucose was 32.5, 32.4, 35.7 and $30.3 \mathrm{~g} / 100 \mathrm{~g}$, respectively for Nampula, Zambezia, Manica and Sofala. The observed differences are attributed to the variable vegetation existing in provinces. The level of sucrose was less than $1 \mathrm{~g} / 100$ $\mathrm{g}$ in all cases (LOQ, Limit of Quantification of the method)

229 The fructose and glucose ratio $(\mathrm{F} / \mathrm{G})$ provides an indication of the capability of crystallisation of honey (Tosi, Lucero, \& Bulacio, 2004). Although this characteristic does not affect the healthiness of 231 honey, the consumer tends to reject crystallized honey, hence its importance as a criterion of quality 232 in terms of its commercialisation. Crystallisation presents the additional problem of increasing the $\mathrm{a}_{\mathrm{w}}$, 233 on the upper layer, which could lead to enzymatic or microbial spoilage through the growth of 234 osmophilic yeasts (Silva, et al., 2016). In the present work, the average values of F/G ratio, around 1.2, were very similar in the four provinces, the most extreme values being in Nampula province which ranged from 0.9 to 1.5 . Considering that the lower the ratio, the quicker the crystallisation, this province could have samples that are more susceptible to granulation (Juan-Borrás et al., 2014).

238 Free acidity is considered as a quality parameter since its high levels is attributable to fermentation 239 by microorganisms. However, recent studies showed that there is no correlation between yeasts and 240 moulds count and the acidity of honey, but rather this parameter could be more related to the origin of 241 honey such as bee species, flowering, climate or

harvest time (Ananias, Melo, \& Moura, 2013). In reality, honey is characterized by the presence of organic acids in equilibrium with lactone, internal esters and some inorganic ions such as phosphates, sulphates and chlorides (Silva et al., 2016). In any case, European legislation establishes $50 \mathrm{meq} / \mathrm{kg}$ as the maximum limit permitted for marketing (Council Directive 2001/110 relating to honey, 2002). In 
the present study, significant differences between provinces with respect to this parameter were found,

247 with average total values of: $15.5,21.5,14.7$ and $10.9 \mathrm{meq} / \mathrm{kg}$ in Nampula, Zambezia, Manica and

248 Sofala, respectively, and a maximum of $22.3 \mathrm{meq} / \mathrm{kg}$ value in a Zambezia sample. It is worth 249 mentioning that the samples studied in this work were far from this maximum level established as the 250 quality criterion. However, in previous studies about honey from Mozambique (in Sofala and Manica 251 provinces) this value sometimes reached to $49.6 \mathrm{meq} / \mathrm{kg}$ (Zandamela, 2008). In other African countries 252 the ranges of variability of this parameter were similar to those of the present study. Terrab, Díez, \& 253 Heredia (2002) reported between 10.3 to $102.0 \mathrm{meq} / \mathrm{kg}$ in honey from Morocco and Nair \& Maghraoui 254 (2017) from 10.0 to $25.0 \mathrm{meq} / \mathrm{kg}$ in honey from Algeria.

255 The lactonic acidity, considered as the acidity reserve when the honey becomes alkaline, (Baroni et 256 al., 2009), ranged from a minimum of $0.1 \mathrm{meq} / \mathrm{kg}$ in one Nampula sample to $17.6 \mathrm{meq} / \mathrm{kg}$ in one 257 Zambezia sample. These values are similar to those found in honey samples from Central and South 258 of Mozambique (1.2 to $15.3 \mathrm{meq} / \mathrm{kg}$ ) (Zandamela, 2008) as well as in honey from other African 259 countries such as Algeria (2.0 to $5.1 \mathrm{meq} / \mathrm{kg}$ ) (Nair \& Maghraoui, 2017); Morocco (0.5 to $18.5 \mathrm{meq} / \mathrm{kg}$ ) 260 (Terrab et al., 2002). Ethiopia (Belay, Solomon, Bultossa, Adgaba, \& Melaku, 2013), Tanzania 261 (Gidamis, Chove, Shayo, Nnko, \& Bangu, 2004); and from Burkina Faso (Paul, et al., 2013).

262 In the present study, in general, $\mathrm{pH}$ values ranged from 3.5 to around 4.5. Other authors reported 263 similar $\mathrm{pH}$ values in African honeys: 3.50-4.43 from Algeria; 3.80-4.50 Morocco; 3.80-4.50 Tunisia; 264 3.58-4.84 Burkina Faso and 3.87 to 5.12 from South Africa. However, several samples in Sofala 265 province showed values of around 6.3, which could be considered as characteristic of certain types of 266 honey (Zandamela, 2008).

267 In summary, and despite the different outliers specific values shown in some cases, the variability of 268 the quality parameters evaluated in Mozambiquean honey was within the range reported in other types 269 of African honey. 
270

271 There is very little data available about the types of pollen that should be present in honey from

272 Mozambique. For this reason, classifying these honeys according to its botanical origin was a difficult

273 challenge. With this in mind, everything possible was done to reach the maximum classification detail:

274 the taxonomic level (taxa) of identification achieved in this type of honey was always to family, and

275 to genus, species or pollen type whenever possible. Pollen type includes species and/or genus present

276 in the area, which have the same floral spectra and the same, or similar, pollen morphology (Acebes

277 Ginove's et al., 2001).

278 In the present study the simplest qualitative analysis was carried out by identifying the most 279 numerous pollen grains and those grains with specific morphologic characteristics (Moar, 1985). The 280 abundance of each taxa (frequency of pollen appearance) was categorized as follows: dominant or 281 282 predominant pollen (D:> 45\%); secondary pollen (S: 16-45\%); important minor pollen (I: 3-15\%); minor pollen (m: 1-3\%) and pollen present (p: <1\%) (Louveaux, Maurizio, \& Vorwohl, 1978).

A total of 25 taxa were recorded belonging to 16 families (Acanthaceae, Anacardiaceae, Asteraceae, Brassicaceae, Campanulaceae, Caryophyllaceae, Celastraceae, Combretaceae, Convolvulaceae, Cyperaceae, Euphorbiaceae, Fabaceae, Myrtaceae, Nymphaeaceae, Pedaliaceae and Poaceae) as well as one taxa unidentified. The most common family that occurred in the samples was Fabaceae $(80 \%)$, followed by Asteraceae (65\%) and Poaceae (60\%). The family with the most recorded taxas was Fabaceae with 5 representatives (Acacia sp., Brachystegia sp., Astragalus type, Vicia type and Mimosa sp.) followed by Asteraceae with 4 (Vernonia sp., Sigesbeckia sp. and two unidentified). Despite the high conductivities found in these types of honey (which leads to think that those belong to a honeydew honey type), however, honeydew elements were not observed in a significant amount in the microscope. This fact has been observed in Mozambiquean honey as well as in other countries with low levels of humidity (Zandamela, 2008). 
The melissopalynologycal analysis permitted classifying the honey samples in terms of their geographical and botanical origin. Taking into account the similarity of the pollen spectrum of the honeys analysed in each region, it was possible to cluster them. In this sense, within the Nampula region $(\mathrm{N})$, the 20 samples analysed were grouped into four types corresponding to their similarity in 298 floral origin: group I. Predominant pollen, Astragalus type (samples N-11 to N-20); group II. 299 Predominant pollen, Acanthus sp. (samples N-3 to N-6); group III. Predominant pollen, Celastraceae 300 family with a presence greater than $85 \%$ (samples N-7 to N-10) and group IV. Predominant pollen, 301 Brassicaceae family with a presence greater than $90 \%$ (samples N-1 to N-2). In the Sofala region (S), the 20 samples were clustered into 3 different groups: group V. Predominant pollen, Anacardiaceae 303 family and Astragalus type (samples S-1 to S-14); group VI. Predominant pollen, Astragalus type and 304 Myrtaceae family (samples S-15 and S-16) and group VII. Predominant pollen, Asteraceae family 305 (samples S-17 to S-20). In the Manica region (M), the 15 samples were placed into three different groups: group VIII. Predominant pollen, unknown 1 (samples M-7 and M-8). The rest of the Manica samples (M-1 to M-4 and M-11, M-14 and M-15) and (M-5, M-6, M-9, M-10, M-12 and M-13) share their pollen spectrum with the previously mentioned groups V and VII respectively. Samples from the Zambezia region (Z) (Z-1 to Z15) also showed similar pollen spectrum of group V.

310 It is important to mention that the sediment of the sample belonging to Group IV showed an anomaly of high pollen abundance and should be interpreted with caution. This is because the presence of a given pollen type in a honey could not only come to the nectar but also to other sources: inclusion of pollens inside the hive; inclusion of pollens during the extraction process of the honey or even aerial contamination. For this reason, in the case of Group IV pollen analysis does not provide any reliable information about botanical source.

It was observed in the present study that the honey from Nampula could be classified into four exclusive types (group I to IV) not found in the other regions. This is logical since the area of Nampula presents specific tropical vegetation due to the high level of humidity in this geographical area. The 
rest of the provinces, located towards the south-central part of the country, share, in a certain way, a characteristic and similar vegetation which is very different from the northern zone (Nampula). This fact implies that the pollen spectrum of honeys from these zones sometimes share similarities.

Table 1 shows the summarized result of the 8 types of honey according to the similar pollen spectrum (group I to group VIII). Within each group the taxa found have been categorized by their abundance.

\subsection{Volatile compounds}

Table 2 shows the maximum and minimum values of the volatile compounds found in the addition, this table indicates the ANOVA results (F-ratio and significant differences) obtained for these two factors. Of the 48 identified compounds, 28 showed statistical significant differences referring to the factor "province" and 29 to "the pollen spectrum". Volatile fraction, as was the case for the physicochemical quality parameters, colour and sugar content, contains potentially usable information for the differentiation of the studied honeys. Group I (from Nampula) presents outstanding abundance of certain compounds: Alcohols [ethanol (36.85-133.10); propan-2-ol (11.53-41.17); 2-methylpropan1-ol (9.52/38.16); pentanol-1 (78.03/235.40)]; Aldehydes [acetaldehyde (n.d.-3.30)]; Esters [2methylpropanoic acid, ethyl ester (0.32/1.70); ethyl acetate (7.67/34.56); 3-methylbutanoic acid, ethyl ester (1.05/4.86); acetic acid, 2-phenyl ethyl ester (0.34/3.23); Acids[ethanoic acid (0.84/7.36); 2methyl propanoic acid $(0.34 / 3.23)]$; Terpenes [ $\beta$-linalool $(0.27 / 1.68)$. The other Nampula groups (group II, III and IV), in general, also showed significant amounts of most of these compounds in relation to the other provinces, but in smaller quantities than group I. The special abundance in groups III and IV of 5 carbon methyl alcohols, such as 3-Methylbutan-1-ol, could contribute to the freshness of the aroma of these honeys (Castro-Vázquez, L., Díaz-Maroto, M. C., \& Pérez-Coello, M. S. (2007). 
344 With the only exception of some samples from Group I, in general honey from Nampula are poor in 345 aldehydes, whereas Sofala and Manica are mainly abundant in butanal, decanal and 2-methyl-butanal. 346 It is important to mention the presence of furan derived compounds largely identified, especially in 347 Sofala and Manica honey ( 7 and 6 compounds out of the 7 identified, respectively). These compounds 348 could be present as a consequence of inadequate thermal procedures and storage conditions. Also, 349 these furan-derived compounds could be associated with the smoke that beekeepers use to hone the 350 bees and extract the honeycombs from the hive and to minimise their aggressiveness. Therefore, if 351 these practices are not implemented well, they could be a source of contamination to the honey and 352 cause unpleasant flavours. Tananaki, Gounari, \& Thrasyvoulou (2009), reported the presence of 353 certain compounds in honeys that were also present in the smoke used by beekeepers in the combs. 354 They also observed a direct relationship between the type of fuel used (pine needles, cypress leaves, 355 fungus, sawdust, etc.) and the amount and type of compounds generated, five of which were identified 356 by these authors that coincide with those found in the honeys of the present study: 1-(2-furanyl)357 ethanone; 2-methyl dihydro 3(H) furanone, 5-methyl furacarboxaldehyde and 5-ethenyl tetrahydro-5358 trimethyl 2-furanmethanol.

\subsection{Effect of province and pollen spectrum on the parameters analysed}

With the aim of evaluating the general effect that the province of harvest and the pollen spectrum has on all the parameters studied, the principal component analyses (PCA) statistical method was chosen to synthesize the great quantity of information obtained from all these parameters. In this way, an easy and understandable form using an exploratory graphical description permitted to know the relationships between variables. Three separate PCA were performed considering in each case different groups of the variables studied: PCA-1. the physicochemical quality parameters, colour and sugar content exclusively; PCA-2. the volatile compounds exclusively and PCA-3. both groups of variables jointly. In these analyses the average values from the three repetitions for each sample of honey were used. The HMF values were not considered in these analyses because, as mentioned before, 
this parameter is mainly related to the freshness of honey, and therefore is not useful for the differentiation among types of honey.

371 The PCA-3 obtained the best separation between groups, which corresponds to all the variables 372 together (physicochemical quality parameters, colour, sugar content and volatile compounds). PCA-1 373 and PCA-2 information is not shown. Figure 3 shows PCA-3 in which the code for each point refers to: province-batch number (e.g: N-5 code refers to the batch number 5 from Nampula province). In the 375 score plot, samples proximity means a certain similarity among them. It was found that two principal components explained $67 \%$ of the variations in the data set: PC1 $47 \%$ of the variability, PC2 20\%-The groupings observed by the pollen spectrum are overlapped (from group I to VIII). The group I from 378 Nampula (located on the right side of the plane), is clearly differentiated from the rest of the groups by $\mathrm{PC} 1$. The rest of the groups are mainly in the left quadrant. This fact reveals, as previously mentioned, the vast difference between the honey of Nampula from group I and the rest. The general behaviour is that a better grouping is obtained considering the pollen spectrum over the provinces.

The information provided by ANOVA and PCA analyses of the physicochemical parameters and volatile compounds, shows that certain variables contribute more in the differentiation honeys standardized canonical discriminant function coefficients obtained for the model. In the construction of the two first discriminant functions, 14 variables were used. Considering that the higher the absolute value of a standardized canonical coefficient, the more significant a variable is, that most contributed to the discrimination of honeys according to the groups were: electrical conductivity and moisture followed by the volatile compound 3-Methylbutan-1-ol and the free acidity.

The classification results (expressed as percentages) of the discriminant analysis carried out by cross validated procedure, permitted the correct classification of $96.7 \%$ of honeys (supplementary Table 1). Within group VII (from Sofala and Manica), 14.3\% of samples were incorrectly classified placing 

them in group VIII (only from Manica). It could be considered that the proximity between both provinces would imply a certain similarity in the flora and therefore very little difference in the characteristics of the harvested honeys. However, as seen in the pollen analysis, these groups (VII and 397 VIII) do not share the pollen spectrum, at all. Therefore, this confusion could be caused by exogenous 398 components of honey, such as specific volatile compounds (from the smoking practices) or some 399 physicochemical parameters (moisture, colour, etc.).

\section{4. Conclusion}

401 Pollen spectrum more than geographical origin permits distinguishing different types of honey from highlights the importance of beekeeping practices in improving the quality of Mozambiquean honey. Therefore, having a good knowledge of the environmental and human implications belonging to this country, the quality characteristics of honeys is of great help to propose a program of future actions 409 when the apiculture wants to be exploited more thoroughly. These considerations are of great 410 importance when developing beekeeping activities.

\section{Acknowledgements}

412 The authors thank the Ministério de Ciência e Tecnologia Ensino Superior e Técnico Profissional de 413 Moçambique (Project: HEST “Ensino Superior, Ciência e Tecnologia”) and Universidade Pedagógica 414 de Moçambique-Nampula for the grant awarded to Fernando Tanleque Alberto.

\section{$415 \quad$ Figure captions}


Figure 1. Box and whisker plots for all the physicochemical parameters considered in this study: 417 [moisture, $\mathrm{a}_{\mathrm{w}}$, hydroximethylfurfural (HMF), electrical conductivity, colour Pfund, glucose, fructose, 418 F/G ratio, $\mathrm{pH}$ and acidity] for honey from Nampula (N), Zambezia (Z), Manica (M) and Sofala (S).

419 Figure 2. An example of light microscope photomicrographs (x 20) of the eight-pollen spectrum 420 (groups I to VIII) found in the Mozambiquean regions (Nampula, Zambezia, Manica and Sofala). Scale $421 \quad$ bars $=20 \mu \mathrm{m}$.

422 Figure 3. PCA scores (province-batch number) and loadings (physicochemical quality parameters, 423 colour, sugar content, and volatile compounds) plots of the first two components. Nampula (N), 424 Zambezia (Z), Manica (M) and Sofala (S)

\section{References}

426 Acebes Ginovés, J. R., del Arco Aguilar, M., Garcia Gallo, A., León Arencibia, M. C., Pérez de Paz, 427 P. L., Rodríguez Delgado, O., \& Wildpret de la Torre, W. (2001). División Pteridophyta y División 428 Spermatophyta. In Lista de especies silvestres de Canarias (hongos, plantas y animales terrestres), 429 Edited by: Izquierdo, I, Martín, J. L, Zurita, N and Arechevaleta, Tenerife, La Laguna (Canary Is.), 430 Consejería Política Territorial \& Medio Ambiente, Gobierno de Canarias.

431 Anagnostopoulos, C. \& Miliadis, G.E. (2013). Development and validation of an easy multi-residue 432 method for the determination of multiclass pesticide residues using GC-MS/MS and LC-MS/MS in 433 olive oil and olives. Talanta, 112, 1-10.

434 Ananias, K. R., Melo, A. A. M. D., \& Moura, C. J. D. (2013). Analysis of moisture content, acidity 435 and contamination by yeast and molds in Apis mellifera L. honey from central Brazil. Brazilian 436 Journal of Microbiology, 44, 679-683.

437 Baroni, M. V., Arrua, C., Nores, M. L., Fayé, P., del Pilar Díaz, M., Chiabrando, G. A., \& Wunderlin, 438 D. A. (2009). Composition of honey from Córdoba (Argentina): Assessment of North/South 439 provenance by chemometrics. Food Chemistry, 114, 727-733. 
440 Belay, A., Solomon, W. K., Bultossa, G., Adgaba, N., \& Melaku, S. (2013). Physicochemical 441 properties of the Harenna forest honey, Bale, Ethiopia. Food chemistry, 141, 3386-3392.

442 Bogdanov, S. (2009). Harmonized methods of the International Honey Commission. Available at:

$443 \quad$ http://www.bee-hexagon.net/en/network.htm

444 Bradbear, N. (2005). La apicultura y los medios de vida sostenibles, Folleto de la FAO sobre 445 diversificación. Dirección de Sistemas de Apoyo a la Agricultura. Available at: $446 \quad$ http://www.fao.org/docrep/008/y5110s/y5110s00.htm

447 Camino-Sánchez, F. J., Zafra-Gómez, A., Oliver-Rodríguez, B., Ruiz-Naranjo, I., Ruiz-García, J., \& 448 Vílchez, J. L. (2012). Validation of a method for the determination of tributyltin in seawater by stir 449 bar sorptive extraction-liquid chromatography tandem mass spectrometry. Journal of $450 \quad$ Chromatography A, 1263, 14-20.

451 Castro-Vázquez, L., Díaz-Maroto, M. C., \& Pérez-Coello, M. S. (2007). Aroma composition and new 452 chemical markers of Spanish citrus honeys. Food Chemistry, 103, 601-606.

453 Council Directive 2001/110 relating to honey. (2002). Official Journal of the European Communities $454 \quad$ L10, 47-52.

455 Crane, E. (1973). Honey sources of some tropical and subtropical countries. Bee World, 54, 177-186.

456 De Girolamo, A., Ciasca, B., Stroka, J., Bratinova, S., Pascale, M., Visconti, A., \& Lattanzio, V. M. 457 (2017). Performance evaluation of LC-MS/MS methods for multi-mycotoxin determination in maize 458 and wheat by means of international Proficiency Testing. TrAC Trends in Analytical Chemistry, 86, $459 \quad 222-234$.

460 Escriche, I., Oroian, M., Visquert, M., Gras, M. L., \& Vidal, D. (2016). Rheological Properties of 461 Honey from Burkina Faso: Loss Modulus and Complex Viscosity Modeling. International journal 462 of food properties, 19, 2575-2586. 
463 Escriche, I., Tanleque-Alberto, F., Visquert, M., \& Oroian, M. (2017). Physicochemical and 464 rheological characterization of honey from Mozambique. LWT - Food Science and Technology, 86, $465 \quad 108-115$

466 FAOSTAT (2016). Food and Agriculture Organization of the United Nations. Statistic Division. 467 Available at: $h t t p: / / w w w . f a o . o r g / f a o s t a t / e s / \# d a t a / Q L / v i s u a l i z e$.

468 Gidamis, A. B., Chove, B. E., Shayo, N. B., Nnko, S. A., \& Bangu, N. T. (2004). Quality evaluation 469 of honey harvested from selected areas in Tanzania with special emphasis on hydroxymethyl furfural 470 (HMF) levels. Plant Foods for human nutrition, 59, 129-132.

471 Gosling, W. D., Miller, C. S., \& Livingstone, D. A. (2013). Atlas of the tropical West African pollen 472 flora. Review of Palaeobotany and Palynology, 199, 1-135.

473 Hyde, M.A., Wursten, B.T., Ballings, P., \& Coates Palgrave, M. (2018). Flora of Mozambique: Home 474 page. Available at: https://www.mozambiqueflora.com/index.php.

475 Johannsmeier, M. F. (2016). Beeplants of South Africa. Sources of nectar, pollen, honeydew and 476 propolis for honeybees. ISBN: 978-1-928224-17-4. Ed. South African National Biodiversity 477 Institute, Pretoria.

Jooste, A. \& Smith, M. (2004). Report on Honey. External Market Study n ${ }^{\circ} .3$. Ministerio de Industria 479 $\mathrm{e}$ Comercio. Mozambique $3: 2-3$. Available at: 480 http://www.gorongosa.org/sites/default/files/research/024-honey.pdf Research International, 60, 86-94. activity and physico-chemical parameters for the differentiation of honey using a potentiometric electronic tongue. Journal of the Science of Food and Agriculture, 97, 2215-2222. 
487 Louveaux, J., Maurizio, A., \& Vorwohl, G. (1978). Methods of melissopalynology. Bee world, 59, $488 \quad 139-157$.

489 Makawi, S. Z. A., Gadkariem, E. A., \& Ayoub, S. M. H. (2009). Determination of antioxidant 490 flavonoids in Sudanese honey samples by solid phase extraction and High Performance Liquid 491 Chromatography. Journal of Chemistry, 6, 429-437.

492 Malika, N., Mohamed, F., \& Chakib, E. A. (2005). Microbiological and physicochemical properties 493 of Moroccan honey. International Journal of Agricultural Biology, 5, 773-776.

494 Martos, S., Cossentini, M., Ferreres, F., \& Toma-Barbera, F. A. (1997). Flavonoid composition of 495 Tunisian honeys and propolis. Journal of Agricultural and Food Chemistry, 45, 2824-282

496 Meda, A., Lamien, C. E., Romito, M., Millogo, J., \& Nacoulma, O. G. (2005). Determination of the 497 total phenolic, flavonoid and proline contents in Burkina Fasan honey, as well as their radical 498 scavenging activity. Food Chemistry, 91, 571-577.

499 Moar, N. T. (1985) Pollen analysis of New Zealand honey, New Zealand Journal of Agricultural $500 \quad$ Research, 28, 39-70.

501 Nair, S., \& Maghraoui, N. B. (2017). Physicochemical Properties of Honeys Produced in North-West 502 of Algeria. Advances in Food Science and Engineering, 1, 123-128.

503 Nombré, I., Schweitzer, P., Boussim, J. I., \& Rasolodimby, J. M. (2010). Impacts of storage conditions 504 on physicochemical characteristics of honey samples from Burkina Faso. African Journal of Food 505 Science, $4,458-463$.

506 Palynological Database on line, Available at: https://www.paldat.org/info

507 Paul, S., Issa, N., Kwamé, A., \& Joseph, B. (2013). Physico-Chemical and Labeling Control of 508 Imported Honeys in Burkina Faso. Food and Nutrition Sciences, 12, 1266-1270. 
509 Oddo, L. P., Piro, R., Bruneau, É., Guyot-Declerck, C., Ivanov, T., Piskulová, J., ... \& Von der Ohe, 510 W. (2004). Main European uni-floral honeys: descriptive sheets. Apidologie, 35, 38-81.

511 Schüler, L., \& Hemp, A. (2016). Atlas of pollen and spores and their parent taxa of Mt Kilimanjaro 512 and tropical East Africa. Quaternary International, 425, 301-386.

513 Serem, J., \& Bester M.J. (2012). Physicochemical properties, antioxidant activity and cellular 514 protective effects of honeys from southern Africa. Food Chemistry, 133, 1544-1550.

515 Silva, P. M., Gauche, C., Gonzaga, L. V., Costa, A. C. O., \& Fett, R. (2016). Honey: Chemical 516 composition, stability and authenticity. Food Chemistry, 196, 309-323.

517 Sime, D., Atlabachew M., Redi-Abshiroand M., \& Zewde T., (2015). Total phenols and antioxidant 518 activities of natural honeys and propolis collected from different geographical regions of Ethiopia, 519 Chemical Society of Ethiopia 29, 163-172.

520 Tananaki, C., Gounari, S., \& Thrasyvoulou, A. (2009). The effect of smoke on the volatile 521 characteristics of honey. Journal of Apicultural Research, 48, 142-144.

522 Terrab, A., Díez, M. J., \& Heredia, F. J. (2002). Characterisation of Moroccan unifloral honeys by 523 their physicochemical characteristics. Food Chemistry, 7373-379.

524 Tornuk, F., Karaman, S., Ozturk, I., Toker, O. S., Tastemur, B., Sagdic, O., Doganb, M., \& Kayacier, 525 A. (2013). Quality characterization of artisanal and retail Turkish blossom honeys: Determination of 526 physicochemical, microbiological, bioactive properties and aroma profile. Industrial Crops and 527 Products, 46, 124-131.

528 Tosi, E. A., Ré, E., Lucero, H., \& Bulacio, L. (2004). Effect of honey high-temperature short-time 529 heating on parameters related to quality, crystallisation phenomena and fungal inhibition. LWT-Food $530 \quad$ Science and Technology, 37, 669-678 
531 Zandamela, E. M. F. (2008). Caracterización Fisicoquímica y Evaluación Sanitaria de la miel de 532 Mozambique (Doctoral dissertation). Universitat Autónoma de Barcelona (Spain). 
535 Table 1. Types of honey according to the similar pollen spectrum (group I to group VIII). Taxas were classified by abundance (category).

POLLEN SPECTRUM CATEGORIZATION

\begin{tabular}{|c|c|c|c|c|c|c|c|c|}
\hline CATEGORY & \multicolumn{4}{|c|}{ Nampula } & \begin{tabular}{l}
\multicolumn{1}{c}{ Group V } \\
Sofala, Manica, \\
Zambezia
\end{tabular} & $\begin{array}{c}\text { Group VI } \\
\text { Sofala }\end{array}$ & $\begin{array}{c}\text { Group VII } \\
\text { Sofala, Manica }\end{array}$ & $\begin{array}{c}\text { Group VIII } \\
\text { Manica }\end{array}$ \\
\hline $\begin{array}{l}\text { Dominant } \\
\text { pollen }(>45 \%)\end{array}$ & & $\begin{array}{l}\text { Acanthus sp. } \\
\text { (acantaceae) }\end{array}$ & Celastraceae & Brassicaceae & & & & Unknown \\
\hline $\begin{array}{l}\text { Secondary } \\
\text { pollen }(16-45 \%)\end{array}$ & $\begin{array}{l}\text { Astragalus type } \\
\text { Vicia type }\end{array}$ & & & & $\begin{array}{l}\text { Astragalus type } \\
\text { Anacardiaceae }\end{array}$ & $\begin{array}{l}\text { Myrtaceae } \\
\text { Astragalus type }\end{array}$ & $\begin{array}{l}\text { Asteraceae (Vernonia } \\
\text { sp., Sigesbeckia sp., } \\
2 \text { unidentified) }\end{array}$ & \\
\hline $\begin{array}{l}\text { Important } \\
\text { minor pollen (3- } \\
15 \%)\end{array}$ & Poaceae & $\begin{array}{l}\text { Justicia } \mathrm{sp} . \\
\text { (acantaceae) } \\
\text { Asteraceae }\end{array}$ & Vicia type & & $\begin{array}{l}\text { Myrtaceae } \\
\text { Poaceae }\end{array}$ & Asteraceae & $\begin{array}{l}\text { Myrtaceae } \\
\text { Astragalus type }\end{array}$ & Combretaceae \\
\hline $\begin{array}{l}\text { Minor pollen } \\
(<3 \%)\end{array}$ & $\begin{array}{l}\text { Acacia sp. } \\
\text { Asteraceae } \\
\text { Carex type } \\
\text { Brachystegia sp. } \\
\text { Combretaceae } \\
\text { Caryophyllaceae }\end{array}$ & Poaceae & & & $\begin{array}{l}\text { Combretaceae } \\
\text { Asteraceae } \\
\text { Euphorbiaceae }\end{array}$ & Poaceae & $\begin{array}{l}\text { Brachystegia sp. } \\
\text { Unknown } \\
\text { Anacardiaceae }\end{array}$ & $\begin{array}{l}\text { Anacardiaceae } \\
\text { Poaceae }\end{array}$ \\
\hline $\begin{array}{l}\text { Present pollen } \\
(<1 \%)\end{array}$ & & & & & $\begin{array}{l}\text { Carex type } \\
\text { Acacia sp. } \\
\text { Mimosa sp. } \\
\text { Brachystegia sp. } \\
\text { Sesamum sp. } \\
\text { Nymphaeaceae }\end{array}$ & Convolvulaceae & $\begin{array}{l}\text { Caryophyllaceae } \\
\text { Campanulaceae } \\
\text { Acacia sp. } \\
\text { Poaceae }\end{array}$ & Cyperaceae \\
\hline
\end{tabular}


Table 2. Volatile compounds (maximum and minimum expressed as $\mu \mathrm{g} / 100 \mathrm{~g}$ of honey) in honey from Mozambique regarding the province and the pollen spectrum (group I to group VIII). ANOVA results (F-ratio and significant differences) obtained for the factors: "province" and "pollen spectrum group".

\section{PROVINCES}

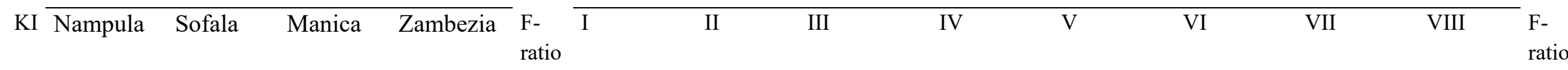

$\mu g / 100 g(\min / \max )$

\section{Acids}

Ethanoic acid

2-Methyl propanoic

acid

3-Methyl butanoic acid

Alcohols

Ethanol

Propan-2-o

Butan-2-ol

2-Methyl 3-buten-2-ol

2-Methylpropan-1-ol

Butan-1-ol

3-Methylbutan-1-ol

Pentanol-1

4-Methyl-3-penten-1-ol

Aldehydes

Acetaldehyde

$\begin{array}{ll}1471 & 0.23 / 7.30 \\ 1602 & \text { n.d. } / 3.20\end{array}$

$951 \quad 6.44 / 133.1$

$0.05 / 31.1 \quad 0.89 / 7.00$

$\begin{array}{lllll}11.67 / 34.6 & 14^{* *} & 36.85 / 133.10 & 6.45 / 21.80 & 16.23 / 22.23\end{array}$

$18.77 / 23.60$

1050 n.d./41.16

n.d./3.64 n.d.

n.d./6.92

$7^{* * *}$

$11.53 / 41.1$

$0.11 / 0.25$ n.d.

n.d./0.44

1063 n.d./1.29

1069 n.d.

$1125 \quad 1.11 / 41.16$

1186 n.d./0.64

1218 n.d./32.12

1226 n.d. $/ 235.10$

1421 n.d./0.43

756 n.d. $/ 3.28$ n.d. n.d./0.07 n.d

$0.03 / 3.60 \quad 0.02 / 0.85 \quad 1.27 / 6.92$

n.d./1.8 n.d. $/ 0.77$

n.d./2.92

$0.42 / 2.06$

n.d.

n.d.

n.d./0.18

n.d./0.11
$0.08 / 0.29 \quad 4^{* *} \quad$ n.d./3.28

n.d.

n.d./n.d.

n.d. n.d./0.30

n.d.

n.d.

n.d. 
881 n.d.

n.d./1.01

$0.27 / 0.17 \quad$ n.d.

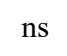

n.d.

n.d.

n.d.

$\begin{array}{llll}\text { n.d./0.64 n.d./0.25 n.d. } & 3^{*} \quad \text { n.d. }\end{array}$

n.d.

n.d.

n.d.

n.d./0.18

n.d./0.19

938 n.d./4.46

$\begin{array}{lll}\text { n.d./3.42 } & 0.20 / 1.47 \quad \text { n.d./0.27 }\end{array}$

ns $\quad 0.16 / 4.47$

n.d.

n.d./0.17

1535 n.d.

n.d.

n.d./0.06 n.d.

ns n.d.

n.d.

n.d.

n.d.

Benzaldehyde

1581 n.d./0.84

Esters

Acetic acid methyl

830 n.d./0.10

n.d./0.04 n.d.

ns $\quad$ n.d./0.11

n.d.

0.0/n.d.

n.d.

n.d./0.04

$898 \quad 1.3 / 34.50$

n.d./1.34

$0.07 / 0.47 \quad 1.42 / 9.34$

$11^{* * *} \quad 7.67 / 34.56$

1054 n.d.

n.d.

n.d.

n.d./0.09 $64^{* * *}$ n.d.

$1.37 / 2.94 \quad 1.44 / 2.77$

$2.73 / 5.25$

n.d.

$0.08 / 9.35$

n.d.

n.d./0.13

$10^{* * *} \quad 0.16 / 0.72$

n.d.

n.d.

n.d./0.07

$0.11 / 0.47$

$11^{* * *} \quad 1.05 / 4.86$

n.d.

$0.39 / 0.68$

.

n.d./0.30

$0.24 / 1.12$

$31^{* * *} \quad$ n.d. $/ 1.24$

$0.28 / 0.4$

n.d.

n.d./1.10 n.d./0.13 $4^{*} \quad$ n.d.

n.d.

n.d.

n.d. $/ 0.38 \quad 8^{* *} \quad 0.34 / 3.23$

n.d./0.

Acetic acid, 2-phenyl ethyl ester

\section{Furanes}

\section{2,5-dimethylfurane}

2-Methyl-dihydro-

3(H)-Furanone
1847 n.d./3.22

n.d.

n.d.

(d.

$0.34 / 3.23$

\begin{tabular}{|c|c|c|c|c|}
\hline 990 n.d. & n.d./0.27 & n.d. & n.d. & ns \\
\hline 252 n.d. & n.d. $/ 0.47$ & n.d./0.19 & n.d. & $\mathrm{ns}$ \\
\hline
\end{tabular}

$\begin{array}{ll}\text { n.d. } & \text { n.d. } \\ \text { n.d. } & \text { n.d. }\end{array}$

\begin{abstract}
n.d.
n.d.
\end{abstract}

n.d. $/ 0.27$
n.d. $/ 0.52$

n.d.

n.d.

n.d./0.09

$0.07 / 1.01$

n.d./0.50

$.20 / 3.42$

n.d./0.06

n.d./0.49

$0.06 / 0.09$

d./0.42 n.d. ns

$0.07 / 1.90 \quad 0.14 / 0.17 \quad 23^{* * *}$

n.d. n.d. ns

n.d. $\quad$ n.d. $26^{* * *}$

n.d. $\quad$ n.d. $27^{* * *}$

n.d./0.10 n.d. $3^{*}$

n.d./1.11 n.d. $3^{*}$

n.d./0.38 n.d. $\quad$ n.d. $\quad$ n.d. $17^{* * *}$ 
Linalool oxide

2-Furaldehyde

1-(2-Furanyl)-ethanone

2-Furaldehyde, 5-

methyl-

2-Furanmethanol

\section{Hydrocarbons}

Octane

Toluene

Ethylbenzene

\section{Ketones}

Acetone

2-Butanone

2-Pentanone

Limonene

3-Hydroxy 2-Butanone

1-Hydroxy 2-

Propanone

\section{Nitrogen compounds}

2-Methylpropanenitrile

2-Methylbutanenitrile

Sulfur compounds

Dimethyl sulfide

\section{Terpenes}

\begin{tabular}{|c|c|c|c|c|c|c|c|c|c|c|c|c|c|c|}
\hline 1464 & n.d./10.0 & n.d./0.83 & $0.17 / 3.6$ & $0.97 / 3.43$ & $7^{* * *}$ & n.d./10.06 & $0.14 / 0.17$ & $0.70 / 1.58$ & $0.13 / 0.20$ & $0.08 / 3.63$ & $0.05 / 0.06$ & n.d./0.66 & $0.28 / 0.36$ & $5^{* *}$ \\
\hline 1502 & n.d./0.17 & n.d./1.28 & $0.05 / 13.43$ & n.d./3.85 & $13^{* * *}$ & n.d. & n.d. & n.d./0.16 & $0.04 / 0.18$ & $0.02 / 13.43$ & $0.51 / 0.71$ & n.d. $/ 5.00$ & $1.71 / 2.22$ & $\mathrm{~ns}$ \\
\hline 1547 & n.d./0.11 & n.d./0.05 & n.d./0.68 & n.d./0.13 & $4^{*}$ & n.d. & n.d. & n.d./0.11 & n.d. & n.d./0.69 & $0.03 / 0.05$ & n.d./0.15 & n.d. & $\mathrm{ns}$ \\
\hline 1627 & n.d./0.12 & n.d./0.35 & $0.02 / 1.13$ & n.d./0.20 & $4^{*}$ & n.d. & n.d. & n.d. & $0.07 / 0.13$ & n.d./1.14 & $0.19 / 0.35$ & n.d./0.32 & $0.06 / 0.09$ & $\mathrm{~ns}$ \\
\hline 1646 & n.d. & n.d./0.18 & n.d./1.53 & n.d./0.39 & ns & n.d. & n.d. & n.d. & n.d. & n.d./1.54 & $0.12 / 0.18$ & n.d./0.27 & n.d. & $\mathrm{ns}$ \\
\hline 796 & n.d./0.22 & n.d./0.15 & n.d./0.09 & n.d. & $\mathrm{ns}$ & n.d. & n.d. & n.d./0.22 & n.d. & n.d./0.09 & $0.10 / 0.16$ & n.d./0.05 & $0.04 / 0.05$ & $5^{* *}$ \\
\hline 1060 & n.d. $/ 1.0$ & n.d./0.39 & n.d./0.08 & n.d. & $8^{* *}$ & n.d./0.71 & $0.78 / 1.03$ & n.d. & n.d. & n.d. & $0.04 / 0.05$ & n.d./0.39 & n.d. & $34^{* * *}$ \\
\hline 1142 & n.d./0.26 & n.d. & n.d. & n.d. & ns & n.d. & n.d./0.27 & n.d. & n.d. & n.d. & n.d. & n.d. & n.d. & $4^{*}$ \\
\hline
\end{tabular}

850 n.d./0.71

n.d. $/ 0.29 \quad 0.02 / 0.60$

ns n.d./0.72

n.d./0.37 n.d.

n.d.

n.d./0.62

n.d.

n.d./0.78

n.d.

929 n.d./0.73 n.d./0.05 n.d. $\quad$ n.d. $\quad 5^{*}$ n.d./0.74 $\quad$ n.d. $\quad$ n.d.

1010 n.d.

n.d./0.08

n.d./0.12 n.d.

ns $\quad$ n.d. $/ 0.40$

n.d. n.d.

n.d.

n.d.

$0.02 / 0.05$

n.d.

n.d./0.08

n.d. n.d./0.60 n.d.

ns n.d.

n.d. n.d.

n.d.

n.d./0.11

n.d.

n.d./0.26 n.d.

n.d.

1261 n.d./1.39

$0.02 / 1.21 \quad 0.04 / 0.88 \quad 0.10 / 0.20$

$0.22 / 0.43 \quad 0.19 / 0.46$

$0.02 / 0.88$

$0.30 / 0.39$

$0.21 / 1.2$

n.d/2.11

$0.62 / 0.66$

n.d./0.29

1153 n.d./0.57

n.d. n.d./0.10 n.d.

$5^{*} \quad$ n.d.

n.d.

n.d.

n.d.

n.d./0.11

n.d.

n.d.

n.d./0.07

n.d.

n.d. 0.26

ns n.d./0.57 n.d. n.d.

n.d.

n.d.

n.d./1.94

$0.01 / 0.03$

n.d./0.56

$0.20 / 0.26$ ns n.d. n.d. n.d. 


\begin{tabular}{|c|c|c|c|c|c|c|c|c|c|c|c|c|c|c|c|}
\hline Limonene & 1214 & n.d. & n.d. & n.d. $/ 0.60$ & n.d. & ns & n.d. & n.d. & n.d. & n.d. & n.d./0.26 & n.d. & n.d. & n.d. & ns \\
\hline$\beta$-linalool & 1695 & n.d./1.68 & n.d. $/ 2.86$ & n.d./0.7 & n.d./0.94 & ns & $0.27 / 1.68$ & n.d. & $0.20 / 0.45$ & n.d. & n.d./0.95 & n.d. & n.d. $/ 2.86$ & n.d. & $4^{*}$ \\
\hline
\end{tabular}

538 (ns: non significant; ${ }^{*} p<0.05 ;{ }^{* *} p<0.01 ; * * * p<0.001$ )

539

Table 3. Standardized canonical discriminant function coefficients

\begin{tabular}{lcc}
\hline Variables & $\begin{array}{c}\text { Function 1 } \\
\mathbf{6 8 \%}\end{array}$ & $\begin{array}{c}\text { Function 2 } \\
\mathbf{1 8 \%}\end{array}$ \\
\hline Butan-2-ol & -0.593 & 0.286 \\
2-Methyl-1,3-pentanedioic & -0.789 & 0.862 \\
Toluene & -0.587 & -0.071 \\
2-Methybutanenitrile & 0.082 & 0.867 \\
Pentan-1-ol & 0.269 & -0.266 \\
3-Methylbutan-1-ol & 2.877 & -0.977 \\
Decanal & 0.070 & 0.294 \\
Moisture & -3.226 & -0.076 \\
Electrical conductivity & 5.197 & -2.186 \\
Fructose & 0.358 & 1.146 \\
Glucose & -1.289 & -1.867 \\
pH & 0.527 & 0.770 \\
Free acidity & -1.319 & 1.334 \\
Lactonic acidity & -0.680 & 0.599 \\
\hline
\end{tabular}




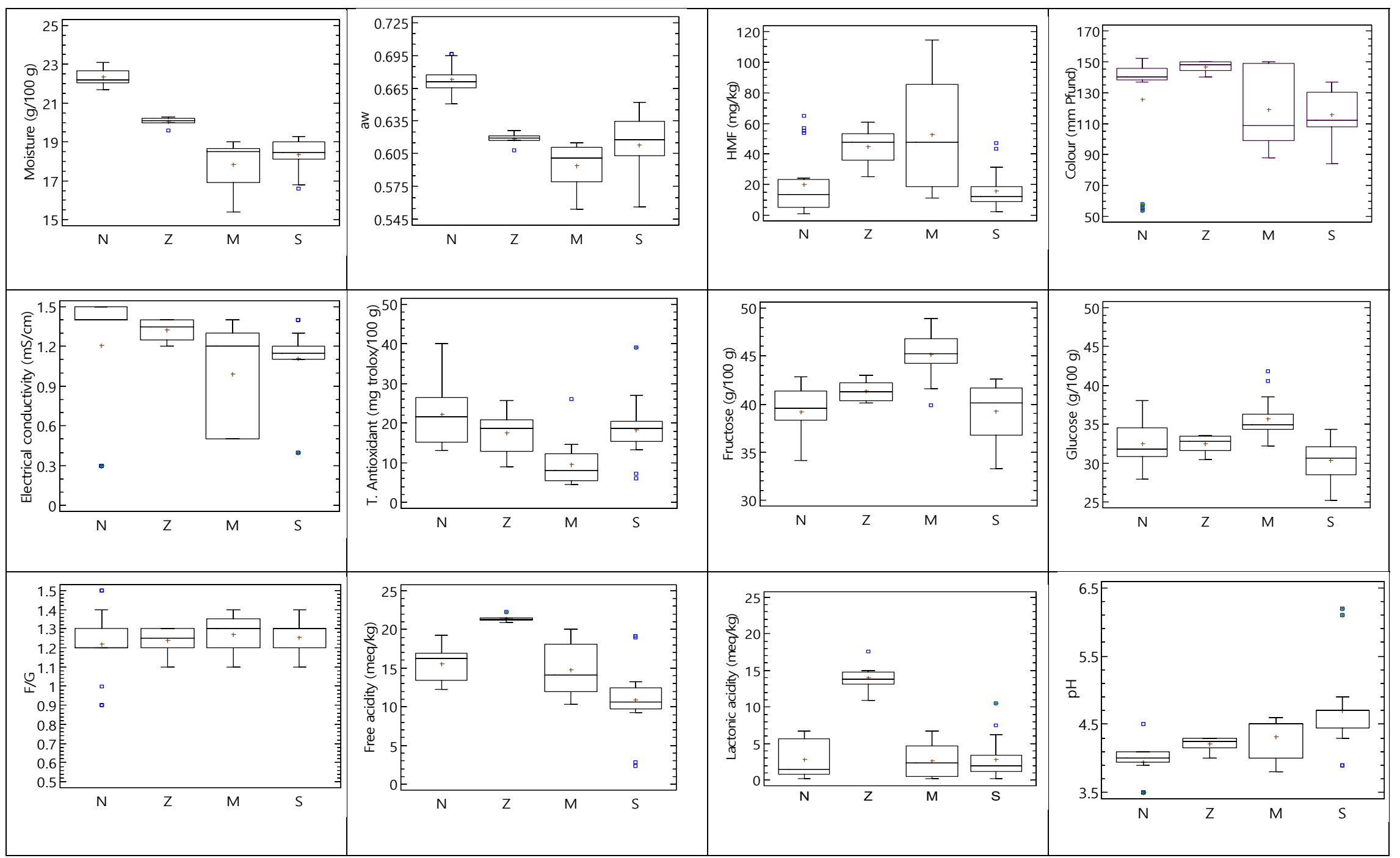

Figure 1. 

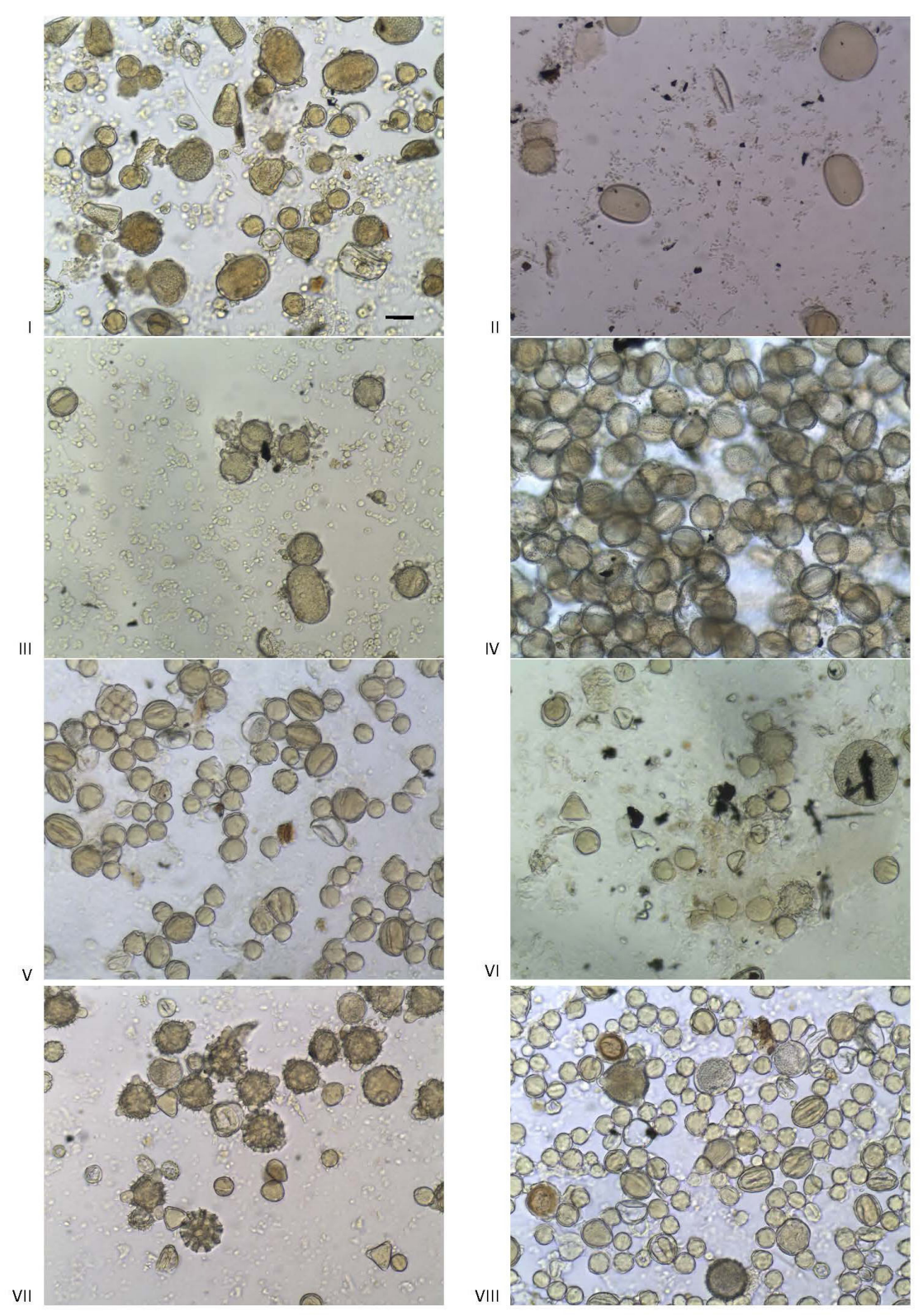

545 Figure 2. 

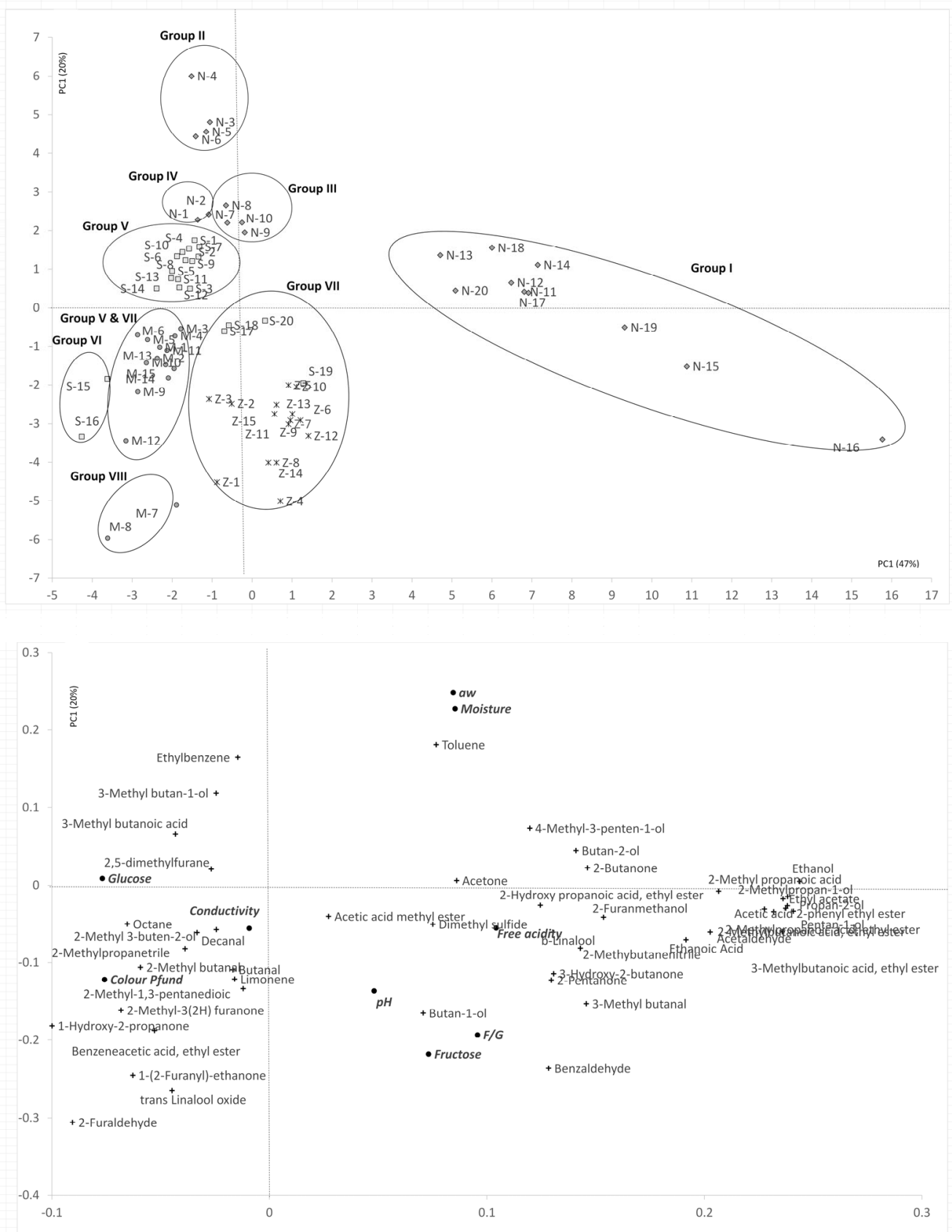

$547 \quad$ Figure 3. 